\title{
Estimation of the burden of cardiovascular disease attributable to modifiable risk factors and cost-effectiveness analysis of preventative interventions to reduce this burden in Argentina
}

Adolfo Rubinstein ${ }^{1,2^{*}}$, Lisandro Colantonio ${ }^{1}$, Ariel Bardach ${ }^{1,3}$, Joaquín Caporale ${ }^{1,4}$, Sebastián García Martí ${ }^{1,2}$, Karin Kopitowski ${ }^{2}$, Andrea Alcaraz ${ }^{1}$, Luz Gibbons ${ }^{1}$, Federico Augustovski ${ }^{1,2}$, Andrés Pichón-Rivière ${ }^{1}$

\begin{abstract}
Background: Cardiovascular disease (CVD) is the primary cause of mortality and morbidity in Argentina representing $34.2 \%$ of deaths and $12.6 \%$ of potential years of life lost (PYLL). The aim of the study was to estimate the burden of acute coronary heart disease (CHD) and stroke and the cost-effectiveness of preventative population-based and clinical interventions.

Methods: An epidemiological model was built incorporating prevalence and distribution of high blood pressure, high cholesterol, hyperglycemia, overweight and obesity, smoking, and physical inactivity, obtained from the Argentine Survey of Risk Factors dataset. Population Attributable Fraction (PAF) of each risk factor was estimated using relative risks from international sources. Total fatal and non-fatal events, PYLL and Disability Adjusted Life Years (DALY) were estimated. Costs of event were calculated from local utilization databases and expressed in international dollars (I\$). Incremental cost-effectiveness ratios (ICER) were estimated for six interventions: reducing salt in bread, mass media campaign to promote tobacco cessation, pharmacological therapy of high blood pressure, pharmacological therapy of high cholesterol, tobacco cessation therapy with bupropion, and a multidrug strategy for people with an estimated absolute risk $>20 \%$ in 10 years.
\end{abstract}

Results: An estimated total of 611,635 DALY was lost due to acute CHD and stroke for 2005. Modifiable risk factors explained $71.1 \%$ of DALY and more than $80 \%$ of events. Two interventions were cost-saving: lowering salt intake in the population through reducing salt in bread and multidrug therapy targeted to persons with an absolute risk above 20\% in 10 years; three interventions had very acceptable ICERs: drug therapy for high blood pressure in hypertensive patients not yet undergoing treatment (I\$ 2,908 per DALY saved), mass media campaign to promote tobacco cessation amongst smokers (I\$3,186 per DALY saved), and lowering cholesterol with statin drug therapy (I\$ 14,432 per DALY saved); and one intervention was not found to be cost-effective: tobacco cessation with bupropion (I\$59,433 per DALY saved)

Conclusions: Most of the interventions selected were cost-saving or very cost-effective. This study aims to inform policy makers on resource-allocation decisions to reduce the burden of CVD in Argentina.

\section{Background}

Chronic diseases are increasing in developing countries and cardiovascular diseases account for 17.7 million

\footnotetext{
* Correspondence: arubinstein@iecs.org.ar

'Institute for Clinical Effectiveness and Health Policy (IECS), Buenos Aires, Argentina

Full list of author information is available at the end of the article
}

annual deaths around the world, constituting $11 \%$ of estimates for the global burden of disease. It is estimated that mortality due to coronary heart disease (CHD) and stroke will increase by approximately $145 \%$ among men and women from 1990 to 2020 in Latin America, compared with a $28 \%$ increase for women and a $50 \%$ increase for men over the same period in developed countries [1].

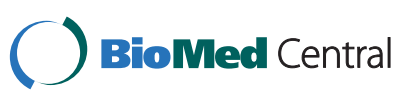


In Argentina, chronic non-communicable diseases account for more than $50 \%$ of the overall morbidity and mortality. In fact, the age-adjusted mortality rate of cardiovascular disease, including CHD and stroke was 206.4 per 100,000 (265.4 for men and 161.8 for women), representing $34.2 \%$ of deaths and $12.6 \%$ of years of potential life lost [2]. Adjusted mortality rates for noncommunicable diseases, as well as Potential Years of Life Lost (PYLL) have declined steadily since 1987, while mortality rates of communicable, maternal, perinatal and nutritional conditions have remained relatively constant in the same 20-year period. Still, the adjusted rate for non-communicable chronic diseases has been five to six times the rate of communicable diseases in Argentina, and the absolute number of deaths is increasing due to the increasingly elderly population [3].

In common with many other Latin American countries, Argentina falls into an intermediate mortality group where the main risk factors for disease are hypertension, an elevated body mass index (BMI), alcohol abuse and smoking [4]. Elevated BMI is due to excess calories and insufficient activity, and a large proportion of hypertension is due to these same lifestyle risks in addition to a poor diet quality. Primary data describing the prevalence and distribution of cardiovascular risk factors in Argentina has recently been obtained through two different population-based sources: the 2005 Ministry of Health National Risk Factor Survey [5]; and the Cardiovascular Risk Factor Multiple Evaluation in Latin America (CARMELA) [6]. There is strong evidence that a $50 \%$ reduction in cardiovascular deaths can be attributable to the reduction of just three modifiable risk factors, namely tobacco use, high blood pressure and elevated cholesterol [7]. In Latin America, the majority of cardiovascular risk could be explained by tobacco use, abnormal lipids, abdominal obesity and high blood pressure as shown in the recently published INTERHEART Latin American study [8]. Most cardiovascular diseases are preventable and there is evidence that supports the effectiveness of interventions to reduce the burden of cardiovascular disease through strategies that reduce risk factors. Unfortunately, strategies to manage cardiovascular conditions have been largely developed for high-income countries which may not be affordable to most of the developing world $[9,10]$. Although there has been widespread recognition of the benefit of costeffectiveness evaluation to inform national health systems of priority settings, its potential has not been realized in the vast majority of countries, including Argentina [11]. Nevertheless, cost-effective interventions to prevent cardiovascular disease in developing countries do exist, but have not been widely applied. Specifically, population and community-based interventions appear to be highly cost-effective when they reach large populations, address high mortality and morbidity diseases, and include multi-level integrated efforts. Interventions targeting individuals, especially high cardiovascular risk subjects, are also cost-effective but usually require clinical involvement and more resources. Moreover, recent studies have consistently shown the cost-effectiveness of interventions that lower the burden of cardiovascular disease in developing countries [12-14].

The aims of this study were 1) to develop an analytical model to estimate the burden of acute CHD and stroke attributable to modifiable cardiovascular disease risk factors in Argentina, 2) to explore the costs of major cardiovascular events, and 3) to calculate the costeffectiveness of different population-based and clinical interventions in order to inform local policy makers on resource-allocation priority setting.

\section{Methods}

We conducted a population-level comparative risk assessment for seven modifiable cardiovascular risk factors to be included in a model to assess their impact on major cardiovascular events: acute myocardial infarction (AMI), other non-infarction ischemic events and stroke. We also estimated the individual and aggregate effect of population-based and clinical interventions that might modify the risks associated to these risk factors. These interventions are supported by evidence in the literature for clinical efficacy and population effectiveness estimates that take into account detection and patient compliance. Cardiovascular risk factors and interventions were modeled for the adult population over 35 years old since they are the usual target for most clinical interventions. Finally, cardiovascular events, Disability Adjusted Life Years (DALY) and interventions costs were derived.

\section{Selection of Risk Factors}

We selected specific risk factors that fulfilled the following criteria: (1) Sufficient evidence was available on the presence and magnitude of likely causal association with CHD and stroke from high-quality epidemiological studies, (2) available interventions existed to modify associated risk, (3) data on risk factor prevalence was available from the First Argentinean Survey of Risk Factors (FASRF) or other nationally representative surveys not subjected to selection bias.

The seven modifiable risk factors selected were: 1) high blood pressure (HBP), 2) high cholesterol, 3) overweight and obesity, 4) elevated fasting glucose level and type-2 diabetes mellitus, 4) tobacco smoking, 5) physical inactivity,

Unfortunately, consumption of vegetables and fruits was ill-defined in the FASRF since the daily quantity of servings was not specified, for which we had to exclude 
this measure for further analysis. Other specific individual dietary factors that would meet criteria for causal effects, such as intake of trans fat, low marine omega-3 (seafood), and low polyunsaturated fat (exchanged for saturated fat) were also excluded because of lack of reliable data on their respective prevalences, after a thorough search of local surveys.

\section{Data Sources}

\section{Risk Factors exposure}

We obtained risk factor prevalence and distribution for each individual enrolled in the FASRF is a nationally representative survey including 41,393 subjects from all districts of the country sampled through a probabilistic multi-stage process [5]. The prevalence of risk factors was obtained from self-reports obtained during an in-person interview that was subsequently validated with direct measures in one district. For those subjects who reported not to have ever measured her/his blood pressure (11.94\%), serum cholesterol (43.25\%) or glycemia $(23.49 \%)$ we considered them as not having the risk factor in the survey. As this assumption could have underestimated their prevalence and population-attributable risk, we developed a logistic regression model to estimate the odds and probabilities for a subject with a certain demographic and risk factor profile to have an abnormal value in each of these three risk factors. These new set of risk factors prevalence were used as an alternative scenario in the sensitivity analysis. STATA v8.0 was used to run these models.

\section{Etiological effects of risk factors on disease-specific} mortality

We obtained the relative risk for $\mathrm{CHD}$ and stroke attributable to each risk factor for each exposure category (since all risks were measured in categories in the FASRF), based on published observational studies, systematic reviews or meta-analyses of epidemiological studies. In previous observational studies used for effect sizes, the majority had adjusted for potential confounding factors. Each relative risk used in our analysis represents the best judgment of the evidence for the effect of risk factor exposure on disease-specific mortality. The etiological effect sizes along different age-strata and gender are shown in Table 1.

\section{Disease-specific deaths}

The number of deaths by CHD (ICD- 10 codes I $20 \times$, I24x and $\mathrm{I} 25 \times$ for non-infarction ischemic events and $\mathrm{I} 21 \times$ and I22 $\times$ for AMI) and stroke (ICD-10 codes I60-I61, I63-I64) were obtained from the National Directorate of Health Statistics of the Argentine Ministry of Health [15].

\section{Estimating mortality and disability attributable to risk factors}

For each risk factor and for each disease causally associated with its exposure, we computed the proportional reduction in disease-specific deaths that would occur if risk factor prevalence had been reduced to zero. This is known as the population-attributable risk (PAR) and measures the total effects of a risk factor (direct as well as mediated through other factors). In order to estimate the PAR of each risk factor, we developed an epidemiological simulation model in Microsoft Excel(r), containing the prevalence and distribution of risk factors according to each age and sex strata as observed in the FASRF [5]. In this way, this matrix of 41,392 registries from the FASRF, representing the Argentine population, was split into all possible combinations of risk factors. Additional risk for each combination was assumed to be the product (multiplication) of the relative risk of the risk factors involved [16]. Finally, the baseline absolute risks for both fatal and non-fatal events for people without any of the selected risk factors were derived considering the overall risk, prevalence and additional risk associated to each combination. The global risk of death (across all combinations and age groups) was calibrated against the overall number of deaths due to CHD and stroke corresponding to Argentina in the year 2005 [15]. Finally, the number of non-fatal events for each death from CHD and stroke was extrapolated using the lethality rate from the Public Hospital registry corresponding to the year 2000 [17].

In addition to the estimation of the prevalence of cardiovascular risk factors and their associated relative risk, the spreadsheet contained the cost and disutility associated with each event in order to obtain a deterministic estimate of the burden of disease, expressed in DALY and overall costs. A DALY is a summary measure that combines years of life lost due to premature death and years of life lived with disability [18]. One DALY can be thought of as one lost year of healthy life. DALYs were calculated based on the model developed by Murray et al. [9].

The duration of disability was estimated by using the software DISMOD II [19]. Disability weights were obtained from two Australian studies on burden of disease $[20,21]$. For the calculation of years of life lost due to premature death, we used a life expectancy at birth of 80 and 82.5 for men and women, respectively, as recommended for global comparisons in the Global Burden of Disease study [9]. Finally, years of life lost due to premature death were obtained from National death registries and years of life lived with disability were obtained by multiplying the estimated number of nonfatal events by each disability weight, for each age gender strata [19].

In order to estimate the PAR associated to each risk factor, a new estimation of deaths, non fatal events, DALY and costs of CHD and stroke were calculated. These estimations were obtained multiplying the basal 
Table 1 List of relative risks included into the model

\begin{tabular}{|c|c|c|c|c|c|c|c|c|}
\hline & \multicolumn{7}{|c|}{ Age groups } & \multirow[b]{2}{*}{ Reference } \\
\hline & $18-39$ & $40-44$ & $45-59$ & $60-64$ & $65-69$ & 70-79 & $80+$ & \\
\hline \multicolumn{9}{|c|}{ Relative risk for coronary heart disease } \\
\hline High blood pressure (m) & 1.3 & 2.0 & 2.2 & 2.7 & 2.7 & 2.7 & 2.2 & [83-85] \\
\hline High blood pressure (w) & 2.5 & 2.5 & 2.2 & 2.7 & 2.7 & 2.7 & 2.2 & {$[83-85]$} \\
\hline High glycemia (m) & 2.0 & 2.0 & 2.0 & 2.0 & 2.0 & 2.0 & 2.0 & [86] \\
\hline High glycemia (w) & 2.5 & 2.5 & 2.5 & 2.5 & 2.5 & 2.5 & 2.5 & [86] \\
\hline Overweight (m) & 1.2 & 1.2 & 1.2 & 1.2 & 1.2 & 1.2 & 1.2 & [87] \\
\hline Overweight (w) & 1.2 & 1.2 & 1.2 & 1.2 & 1.2 & 1.2 & 1.2 & {$[87]$} \\
\hline Obesity (m) & 1.5 & 3.0 & 3.0 & 3.0 & 1.5 & 1.5 & 1.5 & [87] \\
\hline Obesity (w) & 1.5 & 1.5 & 1.5 & 1.5 & 1.5 & 1.5 & 1.5 & [87] \\
\hline High cholesterol (m) & 2.0 & 2.0 & 2.0 & 2.0 & 2.0 & 2.0 & 2.0 & {$[8]$} \\
\hline High cholesterol (w) & 3.4 & 3.4 & 3.4 & 3.4 & 3.4 & 3.4 & 3.4 & {$[8]$} \\
\hline Current smoker (m) & 2.4 & 2.4 & 2.4 & 1.8 & 1.8 & 1.7 & 1.4 & [88] \\
\hline Current smoker (w) & 2.2 & 2.2 & 2.4 & 2.1 & 2.1 & 1.7 & 1.3 & [88] \\
\hline Former smoker (m) & 1.3 & 1.3 & 1.3 & 1.3 & 1.2 & 1.2 & 1.2 & [89] \\
\hline Former smoker (w) & 1.6 & 1.6 & 1.6 & 1.6 & 1.2 & 1.2 & 1.2 & [89] \\
\hline Non-sedentary life style (m) & 0.7 & 0.7 & 0.7 & 0.7 & 0.7 & 0.7 & 0.7 & {$[8]$} \\
\hline Non-sedentary life style (w) & 0.7 & 0.7 & 0.7 & 0.7 & 0.7 & 0.7 & 0.7 & [8] \\
\hline \multicolumn{9}{|l|}{ Relative risk for stroke } \\
\hline High blood pressure (m) & 3.0 & 3.0 & 2.9 & 2.4 & 2.4 & 2.1 & 1.5 & [83] \\
\hline High blood pressure (w) & 2.4 & 2.4 & 2.2 & 2.1 & 2.1 & 1.9 & 1.5 & [83] \\
\hline High glycemia (m) & 2.0 & 2.0 & 2.0 & 2.0 & 2.0 & 2.0 & 2.0 & [86] \\
\hline High glycemia (w) & 2.0 & 2.0 & 2.0 & 2.0 & 2.0 & 2.0 & 2.0 & {$[86]$} \\
\hline Overweight (m) & 1.2 & 1.2 & 1.2 & 1.2 & 1.2 & 1.2 & 1.2 & [87] \\
\hline Overweight (w) & 1.1 & 1.1 & 1.1 & 1.1 & 1.1 & 1.1 & 1.1 & {$[87]$} \\
\hline Obesity (m) & 1.6 & 1.6 & 1.6 & 1.6 & 1.6 & 1.6 & 1.6 & {$[90]$} \\
\hline Obesity (w) & 1.3 & 1.3 & 1.3 & 1.3 & 1.3 & 1.3 & 1.3 & [90] \\
\hline High cholesterol (m) & 1.2 & 1.2 & 1.2 & 1.2 & 1.2 & 1.2 & 1.2 & [91] \\
\hline High cholesterol (w) & 1.2 & 1.2 & 1.2 & 1.2 & 1.2 & 1.2 & 1.2 & [91] \\
\hline Current smoker (m) & 2.4 & 2.4 & 2.4 & 1.8 & 1.8 & 1.7 & 1.4 & [88] \\
\hline Current smoker (w) & 2.2 & 2.2 & 2.2 & 2.1 & 2.1 & 1.7 & 1.3 & [88] \\
\hline Former smoker (m) & 1.0 & 1.0 & 1.0 & 1.0 & 1.0 & 1.0 & 1.0 & [89] \\
\hline Former smoker (w) & 1.3 & 1.3 & 1.3 & 1.3 & 1.0 & 1.0 & 1.0 & [89] \\
\hline Non-sedentary life style (m) & 0.8 & 0.8 & 0.8 & 0.8 & 0.8 & 0.8 & 0.8 & [92] \\
\hline Non-sedentary life style (w) & 0.8 & 0.8 & 0.8 & 0.8 & 0.8 & 0.8 & 0.8 & [92] \\
\hline
\end{tabular}

m: men; w: women.

absolute risk by the product of the relative risks involved in each combination stratum, assuming a relative risk equal to 1 for the index risk factor, weighted by its respective prevalence. Overall deaths, non fatal events, DALY and costs between the estimation for Argentina in 2005 and the new estimation without the index risk factor, was assumed to be the PAR attributable to that particular risk factor. We programmed a macro using Python language [22], in which we performed 1,000 iterations of the prevalence for each combination of risk factors assuming a binomial distribution. Therefore, a new absolute risk was obtained in each iteration, and new estimations of total deaths, non fatal events, DALY and costs were obtained. Finally, we used the empirical PAR distribution to estimate the $95 \%$ confidence interval (95\%CI) using the percentile method. 


\section{Definition and Selection of Interventions}

Different population-based and clinical interventions to reduce cardiovascular disease burden were explored considering not only the evidence of efficacy and effectiveness [23] but also the feasibility to be implemented in Argentina. Relative risk reductions of the interventions were adjusted by population effectiveness measures taking into account target population coverage as well as patient compliance. All interventions have a time horizon of 5 years after which maximum population effectiveness is assumed. The evidence about population effectiveness of mass media campaign targeted to the promotion of physical activity [24-27], salt reduction in food [28,29], control of overweight and obesity [30-35], and promotion of healthy habits $[36,37]$ was non-conclusive, and hence these interventions were not included in the model. On the other hand, evidence on the effectiveness of media campaigns against smoking was generally strong and local programs had already been implemented [38-42]. Efficacy of interventions were modeled as a relative risk reduction or by a reduction on risk factor prevalence. Effect sizes and joint effect of interventions used in the analysis were based on systematic reviews of randomized trials and meta-analysis, when possible. Intervention effects with their corresponding relative risks estimates are shown in Table 2.

\section{Population based-interventions}

Lowering salt intake in the population through reducing salt in bread A program involving the cooperation between the Government, consumer associations and the Bakery Chambers in an effort to reduce 1 gram of salt per 100 grams of bread. Argentina has an average individual consumption of 12 grams of salt per day, 3.4 grams coming from bread. Local experiences showed that it is possible to reduce the amount of salt in bread without being detected as less palatable. At present, there is a pilot training program implemented in selected cities in Argentina to make bakers reduce salt in bread by using special salt dispensers [43]. This intervention could imply a population-wide reduction of 1.33 $\mathrm{mmHg}$ of systolic blood pressure per person and $1 \%$ of the PAR of CHD and stroke $[28,29,44]$.

Mass Media Campaign to promote tobacco cessation This program of the National Ministry of Health involves an annual campaign through four TV spots, six radio spots and written material in major newspapers, magazines and public spaces. Costs were retrieved from data from previous campaigns of the National Ministry of Health. This intervention would reduce the prevalence of smoking by $7 \%[38-42,45]$.

\section{Individual (clinical) interventions}

Treatment of high blood pressure Interventions involved lifestyle change promotion and pharmacological therapy to achieve blood pressure control (SBP/DBP less than 140/90). Target population was composed of adults over 35 years old with the diagnosis of high blood pressure and no treatment (over 1.3 millions of Argentine population representing $8.2 \%$ people older than 35 years old), estimating for this intervention a relative risk reduction of $44 \%$ for CHD and $49 \%$ for stroke [13]. We assumed that $40 \%$ of the population would take one drug, $40 \%$ two drugs and $20 \%$ three or more drugs. The drugs and daily doses evaluated were hydrochlorothiazide $(25 \mathrm{mg})$, atenolol $(50 \mathrm{mg})$, enalapril $(10 \mathrm{mg})$, and amlodipine $(10 \mathrm{mg})$, and the treatment mix was $50 \%$ of the population taking thiazides, $20 \%$ atenolol, $20 \%$ angiotensin-converting enzyme inhibitor and 10\% amlodipine [46]. The same efficacy for each drug category was also assumed. Analysis indicated that these interventions, with a $50 \%$ rate of disease detection and $50 \%$ drug compliance as indicated by the Canadian Hypertension Guidelines [47], would reduce PAR of cardiovascular disease and stroke by $8 \%$.

Table 2 Effectiveness of selected interventions

\begin{tabular}{|c|c|c|}
\hline Intervention & Efficacy & References \\
\hline \multicolumn{3}{|l|}{ Population based interventions } \\
\hline Mass Media Campaign promote tobacco cessation & $\begin{array}{l}\text { Reduction of current smoker } \\
\text { prevalence: } 7 \%\end{array}$ & {$[38-42,45]$} \\
\hline Reducing salt in bread & RR: 0.99 & {$[28,29]$} \\
\hline \multicolumn{3}{|l|}{ Clinical interventions } \\
\hline Bupropion treatment for tobacco cessation & Annual cessation rate: $28 \%$. & {$[49,50]$} \\
\hline Pharmacological high blood pressure treatment* & $\begin{array}{l}\text { For } C H D: R R=0.66 \\
\text { For stroke: } R R=0.51\end{array}$ & [13] \\
\hline Pharmacological high cholesterol treatment with atorvastatin & $\begin{array}{l}\text { For } C H D: R R=0.77 \\
\text { For stroke: } R R=0.81\end{array}$ & {$[13,55]$} \\
\hline $\begin{array}{l}\text { Treatment with four drugs (Polypill strategy) for people with an absolute cardiovascular risk of } \\
\text { more than } 20 \% \text { at } 10 \text { years }\end{array}$ & $\begin{array}{l}\text { For } C H D: R R=0.34 \\
\text { For stroke: } R R=0.32\end{array}$ & {$[12,13,53-55]$} \\
\hline
\end{tabular}

CHD: Coronary Heart Disease, RR: relative risk.

* Include: atenolol, enalapril, amlodipine and hidroclorothiazide.

** Include: aspirine, enalapril, amlodipine and atorvastatin. 
Treatment of high cholesterol This intervention involved promotion of low-cholesterol diet and use of statins (atorvastatin $10 \mathrm{mg}, 20 \mathrm{mg}$ and $40 \mathrm{mg}$ for $50 \%$, $40 \%$ and $10 \%$ of the target population, respectively), according to local estimates and assumptions. Target population was adults over 35 years old with high cholesterol and no treatment (almost one million people representing $5.2 \%$ of people older than 35 years old). Achieving a cholesterol target of less than $240 \mathrm{mg} / \mathrm{dl},(6.2$ $\mathrm{mm} / \mathrm{l}$ ) would provide an estimated reduction of $8 \%$ of the PAR of CHD and stroke with a 50\% detection and 50\% drug compliance rate according to ATP III [48].

Tobacco cessation therapy Motivational interventions from health professionals and drug therapy with bupropion for a 2-month period (300 mg per day) would result in an estimated reduction of $4 \%$ of the PAR of CHD and stroke [49]. In most studies with bupropion for tobacco cessation, the annual quitting rate of smokers was $28 \%$ vs. $12 \%$, as compared to placebo [50,51]. According to a recent national survey of tobacco prevalence, only $11 \%$ of total smokers in Argentina were willing to quit smoking and therefore were considered the target population for this intervention [52]. According to these estimates, the spontaneous annual cessation rate would be $1.32 \%$ ( $12 \%$ of the $11 \%$ of smokers willing to quit) that would raise to $3.08 \%$ with bupropion (28\% $\times 11 \%)$, since we would expect a prevalence reduction of $1.76 \%(3.08 \%-1.32 \%)$.

Treatment based on a population absolute risk approach (Polypill strategy) Since the "Polypill" is not yet in Argentine markets, we designed a pharmacological therapy with 4 pills (hydrochlorothiazide $25 \mathrm{mg}$, enalapril $10 \mathrm{mg}$, atorvastatin $10 \mathrm{mg}$ and aspirin $100 \mathrm{mg}$ ), prescribed to people older than 35 years old with an estimated combined risk of a cardiovascular event over the next decade above $20 \%$, based on the data from the FASRF. This intervention would imply a relative risk reduction of CHD of $66 \%(\mathrm{RR}=0.34)$ and of stroke of $68 \%(\mathrm{RR}=0.32)[12,13,53-55]$.

Assuming that at least $50 \%$ of the target population is reached by the intervention, a $50 \%$ patient compliance rate with treatment for this group, and $70 \%$ of provider compliance due to a presumed raised awareness of risks for both subjects, the Polypill strategy would result in a population effectiveness of $17,5 \%$. Relative risks for $\mathrm{CHD}$ and stroke for individuals from this high-risk subgroup were estimated by using the beta coefficients from the Framingham Heart Study [16].

\section{Estimating costs of acute cardiovascular events and interventions \\ Costs of acute events}

Cost categories (i.e. inpatient hospital days, doctor visits, tests, drugs and ancillary services, and diagnostic and therapeutic procedures) for AMI, other non-infarction ischemic events such as unstable angina and stroke were first identified. For each event the quantities and unit prices of inputs were retrieved from hospital databases and other local sources [56-66], as well as expert opinion when necessary. The quantities of each input identified were assessed and multiplied by the unit price of each item to obtain the unit cost of each resource. Finally, the total cost of the acute event resulted from the addition of all of the identified consumed resources in each category.

\section{Costs of interventions}

Costs included program-level expenses associated with management of the interventions (i.e. administration, training and information, dissemination by multiple media sources) and patient-level costs (i.e. primary care visits, ancillary tests and drugs). The quantities of each input required were assessed and multiplied by the unit price of each input for the 5 year intervention implementation period. The quantity of patient-level resource inputs for each intervention (i.e. inpatient hospital days, doctor visits, tests, drugs) were identified from local or international published data if available or expert opinion should the former not be available. Costs of drugs were calculated using a mix of blood pressure lowering drugs composed of $50 \%$ hydrochlorothiazide, $20 \%$ atenolol, $20 \%$ enalapril and $10 \%$ amlodipine, according to a published local study [46]. Cost of blood pressure lowering drugs, atorvastatin and bupropion as well as other input costs and expense data were extracted from local sources [65-67]. Other cost data were obtained from the Health Care Costs Database from the Institute of Clinical Effectiveness and Health Policy [62]. A list of costs and sources of the interventions and selected health events is depicted in Table 3.

Cost of clinical interventions included, in addition to their specific costs of visits, tests and drugs, 290 countrywide training workshops on cardiovascular risk detection, assessment and control targeted to 8,639 general practitioners from the public and private health sector, along the 5 year period of the intervention, with periodic boosters through email and postal mail. Except when explicitly stated, costs related to labor, equipment, capital, overhead or joint costs were regarded as existing, ongoing, or common to all interventions and therefore were excluded in the calculation. We also excluded costs of accessing health interventions that would include the resources used by patients and their families to obtain an intervention (transport costs) as well as productivity gains or losses, as the study was conducted from a purchaser perspective. All costs were calculated in Argentine pesos for the year 2007, requiring in some cases the use of Health and General CPI to adjust for annual inflation, and finally converted and expressed 
Table 3 Interventions and related health events summary costs

\begin{tabular}{lc}
\hline Event cost per hospital admission & 2007 I\$ \\
\hline Coronary Heart Disease & $4,245.39$ \\
Stroke & $3,455.48$ \\
Population-based interventions & \\
Mass Media Campaign promote tobacco cessation* $^{*}$ & $3,164,785.75$ \\
Reducing salt in bread $^{\dagger}$ & $193,576.23$ \\
Individual interventions (yearly cost per person $\neq$ ) & \\
Pharmacological high blood pressure treatment $^{\text {Pharmacological high cholesterol treatment }}$ & 49.72 \\
Bupropion treatment for tobacco cessation $^{\text {Modified Polypill strategy }}$ & 118.79 \\
\hline
\end{tabular}

I\$: international dollars. PPP conversion rate (2007) 1.55 Argentinean peso $=1$ I\$,

* Ten years duration of campaign, with discounting (3\% annual rate).

† Assuming 54 meeting of 30 bakers each (around 800-600 bakers), with discounting ( $3 \%$ annual rate).

‡ Includes health center visits, drug and lab test costs. Programmatic costs were not included (I\$ 1,194,067.52).

Note: Cost of blood pressure lowering drugs, atorvastatin and bupropion as well as other input costs and charges data were extracted from local sources [65-67]. Other cost data were obtained from the Health Care Costs Database by the Institute of Clinical Effectiveness and Health Policy [62].

into international dollars using the Purchase Power Parity conversion rate AR $\$ 1.55=1 \mathrm{I} \$$ [68]. The discounting of long term costs was performed at a $3 \%$ rate.

\section{Perspective}

Since Argentina's healthcare system consists of a multitier system divided in three large sectors: public, social security and private, we incorporated the perspective of the whole Argentine healthcare system as a purchaser of health services.

\section{Calculating cost-effectiveness of interventions}

Cost-effectiveness analysis considers the costs and effects of adding new interventions to current practice or the cost of replacing an existing intervention with another targeting the same condition. In order to estimate the reduction in disease burden related to the reduction of cardiovascular disease, we built a model to predict the burden associated with specific diseases or risk factors to develop disease. We calculated the effect of interventions in our model, assuming that all reduced the relative risk associated with the presence of each cardiovascular risk factor. In the case the effect of the intervention was a reduction of the prevalence (i.e.: tobacco cessation), a new relative risk was estimated as a proportional combination of the relative risk associated with the risk factor (for the proportion of people that were still smokers) and the relative risk of those that no longer had that risk factor (i.e.: former smokers). Finally, the model translated these changes into a new estimation of cardiovascular events, overall costs and DALY lost, specific for age and sex. This estimation was then compared to the estimation without the intervention. In addition, the annual cost of the intervention was imputed for the year analyzed. For each intervention, the Incremental Cost-Effectiveness Ratio (ICER) of the interventions compared to no intervention was measured as cost per averted DALY. Effect sizes and joint effect of interventions used in the analysis were based on systematic reviews of randomized trials and metaanalysis, when possible.

To translate changes in the risk of age and sex specific cardiovascular disease events into changes in population health quantified in terms of DALY, we used a standard methodology described elsewhere [69].

There is no universal criterion that defines a threshold cost-effectiveness ratio, above which an intervention would not be considered cost-effective. We chose to use guidelines specifically intended for international comparisons, as proposed by the Commission on Macroeconomics and Health, which defines interventions with an ICER that is less than three times Gross Domestic Product per capita as a "cost-effective" intervention and as "very cost-effective" if ICER is less than the GDP per capita [70,71]. Argentina's GDP per person in 2007 was estimated in I\$ 13,255.09 [72].

\section{Uncertainty and sensitivity analysis}

We also did a probabilistic, multivariate sensitivity analysis using Monte Carlo simulation [73,74] of 1,000 randomly selected sets of variables, to assess the effects of uncertainty in the prevalence of risk factors, population attributable risk and effect sizes of interventions. In addition, an undiscounted scenario was considered for costs and DALY, and a non age-weighted scenario was also analyzed for DALY.

\section{Results}

We estimated a lethality rate of $11.9 \%$ in men and $18 \%$ in women; and $17.4 \%$ in men and $18.9 \%$ in women, for CHD and stroke, respectively [17]. According to these estimates, about 263,025 annual acute CHD and stroke events would be expected, representing an annual cost of I\$ $1,036,506,958$. More than $60 \%$ of total events and costs are accounted by men. Table 4 shows the estimation of the overall number of annual cardiovascular events in Argentina, burden of disease and costs of events. As observed, more than 600,000 DALYs and almost 400,000 YPLL were lost in 2005 due to CHD and stroke.

\section{Burden of Disease attributable to modifiable cardiovascular Risk Factors}

Population attributable risks, costs of events and DALY lost to cardiovascular disease for the overall risk factors and for each single modifiable risk factor selected, can 
Table 4 Estimation of total cases, costs and burden of disease of acute CHD and stroke

\begin{tabular}{lccc}
\hline & Men & Women & Total \\
\hline Total AMI events [\%] & 62,132 & 24,031 & 86,163 \\
& {$[72.1 \%]$} & {$[27.9 \%]$} & {$[100.0 \%]$} \\
Total non-infarction events [\%] & 51,660 & 23,751 & 75,411 \\
& {$[68.5 \%]$} & {$[31.5 \%]$} & {$[100.0 \%]$} \\
Total stroke events [\%] & 53,432 & 48,018 & 101,450 \\
& {$[52.7 \%]$} & {$[47.3 \%]$} & {$[100.0 \%]$} \\
Total events [\%] & 167,225 & 95,800 & 263,025 \\
& {$[63.6 \%]$} & {$[36.4 \%]$} & {$[100.0 \%]$} \\
Total costs* |\$ [\%] & $667,728,147$ & $368,778,811$ & $1,036,506,958$ \\
& {$[64.4 \%]$} & {$[35.6 \%]$} & {$[100.0 \%]$} \\
Total DALY† [\%] & 293,419 & 318,217 & 611,635 \\
& {$[48.0 \%]$} & {$[52.0 \%]$} & {$[100.0 \%]$} \\
Total PYLLキ [\%] & 218,547 & 175,617 & 394,163 \\
& {$[55.5 \%]$} & {$[44.6 \%]$} & {$[100.0 \%]$} \\
\hline
\end{tabular}

95\%Cl: 95\% confidence interval, AMI: acute myocardial infarction, DALY: disability-adjusted life years, I\$: international dollars, PYLL: Potential Years of Life Lost.

* Only direct medical costs by hospitalization were considered. Costs are measured in 2007 international dollars (I\$).

† With discounting (3\% annual rate), without age weight.

‡ With discounting ( $3 \%$ annual rate).

be seen in Tables 5 and 6, respectively. All risk factors together explained $75 \%$ of fatal and non-fatal acute CHD and stroke events, $82,4 \%$ of acute CHD events (84.0\% in women) and $62.4 \%$ of strokes (66,6\% in men). Similarly, modifiable risk factors explained $75,5 \%$ of costs of acute events and $70.7 \%$ of DALY lost. The most important single risk factor was high BP, explaining 37\% of all CHD and strokes and one-third of all DALY lost in 2005. The rest of the risk factors have similar attributable burden in term of CV events, ranging between $13,9 \%$ (high glycemia) to $18,1 \%$ (physical inactivity). (see Table 6).

\section{Cost-effectiveness of selected interventions}

Table 7 summarizes the results of economic evaluation of the 6 distinct interventions giving their total annual costs and costs per beneficiary, health effects in terms of DALY averted (non age-weighted and 3\% discounted), percent of DALY saved due to cardiovascular disease and average cost-effectiveness ratio for each in I\$ per DALY averted. Two interventions were cost-saving: lowering salt intake in the population through reducing salt in bread and treatment targeted to persons with an absolute risk above $20 \%$ in 10 years (modified polypill strategy). Moreover, the implementation of the polypill strategy was also associated with almost a $2 \%$ decrease in DALY lost to cardiovascular disease. On the other hand, the impact of reducing salt in bread was more limited $(0.11 \%$ of decrease of DALY lost) due in part to the lower extension and magnitude of this intervention. Two interventions had very acceptable ICER: 1) drug therapy for high blood pressure in hypertensive patients not yet under going treatment with an ICER of I\$2,908 per DALY saved and an annual reduction of $2.3 \%$ of cardiovascular disease burden; and 2) mass media campaign to promote tobacco cessation amongst smokers, with an ICER of I\$ 3,186 per DALY saved (0.11\% of cardiovascular disease burden). An additional intervention, lowering cholesterol with statins (I\$ 14,432 per DALY saved), was considered cost-effective according to the guidelines mentioned above. Finally, one intervention, tobacco cessation with bupropion (I\$ 59,433 per DALY saved) was not found to be cost-effective. This is in part because bupropion is much more expensive than blood pressure lowering drugs and also because, as it is not currently covered in the public sector, the government does not usually exert its purchasing power to get lower prices. Following local surveys, we assumed that only $11 \%$ of the population of smokers would be willing to quit smoking each year and consequently start on a program, the population impact of tobacco cessation therapy was much smaller than expected.

Figure 1 shows the ICER of the six distinct interventions along the cost effectiveness plane with their

Table 5 Proportional Burden of Disease and costs attributable to all cardiovascular risk factors potentially modifiable

\begin{tabular}{|c|c|c|c|}
\hline & \multicolumn{3}{|c|}{ Population-attributable Fraction $\%(95 \% \mathrm{Cl})$} \\
\hline & Men & Women & Total \\
\hline Total AMI events (both fatal and non-fatal) & $81.8(81.3-82.2)$ & $84.1(82.8-85.0)$ & $82.4(81.9-82.8)$ \\
\hline Total non-infarction events (both fatal and non-fatal) & $81.5(80.9-82.0)$ & $83.5(81.9-84.7)$ & $82.1(81.5-82.6)$ \\
\hline Total stroke events (both fatal and non-fatal) & $66.6(65.7-67.4)$ & $57.6(56.4-58.8)$ & $62.4(61.6-63.1)$ \\
\hline Total events (both fatal and non-fatal) & $76.8(76.2-77.4)$ & $70.7(69.4-71.7)$ & $74.6(74.0-75.1)$ \\
\hline Total costs* & $77.5(76.9-78.0)$ & $72.0(70.7-73.1)$ & $75.5(75.0-76.0)$ \\
\hline Total DALY ${ }^{\dagger}$ & $76.0(75.5-76.4)$ & $65.8(65.0-66.5)$ & $70.7(70.2-71.1)$ \\
\hline Total PYLL & $76.5(75.9-76.9)$ & $69.6(68.6-70.5)$ & $73.4(72.9-73.9)$ \\
\hline
\end{tabular}

Results of 1,000 iterations, both sexes.

95\% Cl: 95\% confidence interval, AMI: acute myocardial infarction, DALY: disability-adjusted life years, PYLL: Potential Years of Life Lost.

* Only direct medical costs by hospitalization were considered.

† With discounting ( $3 \%$ annual rate), without age weight.

‡ With discounting (3\% annual rate). 
Table 6 Proportional Burden of Disease and costs attributable to each cardiovascular risk factor potentially modifiable

\begin{tabular}{|c|c|c|c|c|c|c|}
\hline \multirow[b]{2}{*}{ Both sexes } & \multirow[b]{2}{*}{ Tobacco use } & \multicolumn{5}{|c|}{ Population-attributable Fraction $\%(95 \% \mathrm{Cl})$} \\
\hline & & $\begin{array}{l}\text { Overweight } \\
\text { and Obesity }\end{array}$ & $\begin{array}{l}\text { High Blood } \\
\text { pressure }\end{array}$ & $\begin{array}{c}\text { High } \\
\text { cholesterol }\end{array}$ & High glycemia & $\begin{array}{l}\text { Physical } \\
\text { inactivity }\end{array}$ \\
\hline $\begin{array}{l}\text { Total AMI events (both } \\
\text { fatal and non-fatal) }\end{array}$ & $22.5(22.2-22.8)$ & $20.9(20.4-21.3)$ & $38.5(37.9-39.1)$ & $25.1(24.4-25.8)$ & $13.9(13.2-14.5)$ & $20.9(20.6-21.2)$ \\
\hline $\begin{array}{l}\text { Total non-infarction events } \\
\text { (both fatal and non-fatal) }\end{array}$ & $18.5(18.1-18.8)$ & $18.6(18.2-19.0)$ & $40.9(40.1-41.5)$ & $26.2(25.2-27.0)$ & $14.8(14.0-15.6)$ & $21.6(21.2-22.0)$ \\
\hline $\begin{array}{l}\text { Total stroke events (both } \\
\text { fatal and non-fatal) }\end{array}$ & $10.8(10.5-11.2)$ & $11.7(11.3-12.0)$ & $32.7(32.0-33.3)$ & $5.8(5.6-6.1)$ & $13.2(12.3-14.0)$ & $13.0(12.7-13.3)$ \\
\hline $\begin{array}{l}\text { Total events (both fatal } \\
\text { and non-fatal) }\end{array}$ & $16.9(16.5-17.2)$ & $16.7(16.3-17.0)$ & $37.0(36.3-37.5)$ & $18.0(17.4-18.5)$ & $13.9(13.1-14.6)$ & $18.1(17.7-18.3)$ \\
\hline Total costs* & $17.3(17.0-17.6)$ & $17.1(16.7-17.4)$ & $37.3(36.6-37.9)$ & $18.9(18.3-19.5)$ & $13.9(13.2-14.7)$ & $18.4(18.1-18.7)$ \\
\hline Total DALY ${ }^{\dagger}$ & $16.1(15.7-16.4)$ & $13.8(13.5-14.0)$ & $36.6(36.1-37.0)$ & $13.4(13.0-13.7)$ & $13.6(13.0-14.2)$ & $15.5(15.2-15.7)$ \\
\hline Total PYLL & $16.6(16.3-16.9)$ & $15.1(14.8-15.4)$ & $37.5(36.9-38.0)$ & $16.6(16.1-17.1)$ & $13.9(13.2-14.6)$ & $16.9(16.6-17.1)$ \\
\hline Men & Tobacco use & $\begin{array}{l}\text { Overweight } \\
\text { and Obesity }\end{array}$ & $\begin{array}{l}\text { High Blood } \\
\text { pressure }\end{array}$ & $\begin{array}{c}\text { High } \\
\text { cholesterol }\end{array}$ & High glycemia & $\begin{array}{l}\text { Physical } \\
\text { inactivity }\end{array}$ \\
\hline $\begin{array}{l}\text { Total AMI events (both } \\
\text { fatal and non-fatal) }\end{array}$ & $26.7(26.2-27.1)$ & $24.7(24.1-25.2)$ & $37.0(36.4-37.6)$ & $19.0(18.3-19.6)$ & $12.4(11.8-13.0)$ & $20.2(19.8-20.6)$ \\
\hline $\begin{array}{l}\text { Total non-infarction events } \\
\text { (both fatal and non-fatal) }\end{array}$ & $23.1(22.6-23.5)$ & $22.3(21.8-22.8)$ & $40.1(39.3-40.8)$ & $19.3(18.6-20.0)$ & $13.5(12.8-14.2)$ & $20.6(20.2-21.2)$ \\
\hline $\begin{array}{l}\text { Total stroke events (both } \\
\text { fatal and non-fatal) }\end{array}$ & $14.2(13.7-14.7)$ & $16.7(16.0-17.3)$ & $35.2(34.3-36.0)$ & $5.2(4.9-5.5)$ & $13.5(12.6-14.4)$ & $12.2(11.7-12.6)$ \\
\hline $\begin{array}{l}\text { Total events (both fatal } \\
\text { and non-fatal) }\end{array}$ & $21.6(21.1-22.0)$ & $21.4(20.9-21.9)$ & $37.4(36.7-38.1)$ & $14.7(14.1-15.2)$ & $13.1(12.4-13.8)$ & $17.8(17.4-18.2)$ \\
\hline Total costs* & $22.0(21.6-22.5)$ & $21.7(21.2-22.2)$ & $37.6(36.8-38.2)$ & $15.2(14.7-15.8)$ & $13.1(12.4-13.8)$ & $18.1(17.7-18.6)$ \\
\hline Total DALY' & $22.1(21.6-22.6)$ & $20.5(20.1-20.9)$ & $38.7(38.1-39.3)$ & $12.1(11.7-12.6)$ & $13.0(12.3-13.7)$ & $15.6(15.3-16.0)$ \\
\hline Total PYLL ${ }^{\ddagger}$ & $21.6(21.1-22.1)$ & $20.7(20.2-21.1)$ & $38.7(38.1-39.3)$ & $13.4(12.9-13.8)$ & $13.1(12.4-13.8)$ & $16.5(16.2-16.9)$ \\
\hline Women & Tobacco use & $\begin{array}{l}\text { Overweight } \\
\text { and Obesity }\end{array}$ & $\begin{array}{l}\text { High Blood } \\
\text { pressure }\end{array}$ & $\begin{array}{c}\text { High } \\
\text { cholesterol }\end{array}$ & High glycemia & $\begin{array}{l}\text { Physical } \\
\text { inactivity }\end{array}$ \\
\hline $\begin{array}{l}\text { Total AMI events (both } \\
\text { fatal and non-fatal) }\end{array}$ & $11.9(11.5-12.3)$ & $11.0(10.5-11.6)$ & $42.4(41.1-43.5)$ & $41.0(39.2-42.7)$ & $17.7(16.2-19.1)$ & $22.6(22.2-23.1)$ \\
\hline $\begin{array}{l}\text { Total non-infarction events } \\
\text { (both fatal and non-fatal) }\end{array}$ & $8.5(8.0-9.0)$ & $10.5(9.9-11.2)$ & $42.5(40.7-44.0)$ & $41.1(38.4-43.1)$ & $17.7(15.8-19.6)$ & $23.7(23.1-24.2)$ \\
\hline $\begin{array}{l}\text { Total stroke events (both } \\
\text { fatal and non-fatal) }\end{array}$ & $7.1(6.8-7.6)$ & $6.1(5.8-6.5)$ & $29.9(28.9-30.8)$ & $6.6(6.1-7.1)$ & $12.8(11.5-14.2)$ & $14.0(13.6-14.3)$ \\
\hline $\begin{array}{l}\text { Total events (both fatal } \\
\text { and non-fatal) }\end{array}$ & $8.6(8.3-9.1)$ & $8.4(8.0-8.9)$ & $36.2(34.9-37.3)$ & $23.8(22.4-24.9)$ & $15.2(13.8-16.8)$ & $18.6(18.1-19.0)$ \\
\hline Total costs* & $8.8(8.4-9.3)$ & $8.7(8.2-9.7)$ & $36.8(35.5-37.9)$ & $25.5(24.1-26.7)$ & $15.5(14.0-17.0)$ & $19.0(18.6-19.5)$ \\
\hline Total DALY ${ }^{\dagger}$ & $10.5(10.1-10.9)$ & $7.6(7.3-7.9)$ & $34.5(33.8-35.2)$ & $14.5(13.9-15.1)$ & $14.1(13.2-15.1)$ & $15.3(15.0-15.6)$ \\
\hline Total PYLL ${ }^{\ddagger}$ & $10.4(10.0-10.8)$ & $8.3(7.9-8.7)$ & $36.0(35.0-36.9)$ & $20.7(19.7-21.6)$ & $14.8(13.6-16.0)$ & $17.3(16.9-17.6)$ \\
\hline
\end{tabular}

Results of 1000 iterations, basal case, both sexes.

95\%Cl: 95\% confidence interval, AMl: acute myocardial infarction, DALY: disability-adjusted life years, PYLL: Potential Years of Life Lost.

* Only direct medical costs by hospitalization were considered.

† With discounting ( $3 \%$ annual rate), without age weight.

‡ With discounting ( $3 \%$ annual rate).

respective probability distribution. The shaded area corresponds to the cost-saving interventions.

\section{Sensitivity Analyses}

We examined the effect of a change in the PAR estimate of the overall risk factors selected along a reasonable range of probabilities, by creating alternative scenarios with different prevalence and distributions of risk factors. We also explored undiscounted and age-weighted DALY as compared to the base case scenario with DALY discounted at 3 percent and non age-weighted.
In all circumstances, the ranking as well as the magnitude of each intervention remained the same. Finally, the results of the probabilistic sensitivity analyses to estimate the uncertainty surrounding the central estimates of each intervention is expressed through the $95 \%$ CI showed in Table 7.

\section{Discussion}

Our study analyzed the FASRF at individual level to estimate the burden of cardiovascular disease in Argentina attributable to modifiable risk factors in order to 
Table 7 Cost effectiveness analysis of selected interventions

\begin{tabular}{|c|c|c|c|c|c|}
\hline Intervention & $\begin{array}{c}\text { Total costs } \\
\text { I\$ }\end{array}$ & $\begin{array}{c}\text { Net Total costs * } \\
\text { I\$ }\end{array}$ & $\begin{array}{l}\text { DALY saved † } \\
\text { DALY }(95 \% \mathrm{Cl})\end{array}$ & $\begin{array}{c}\text { Percent of } \\
\text { DALY saved } \\
\%(95 \% \mathrm{Cl})\end{array}$ & $\begin{array}{c}\text { ICER per DALY } \\
\text { saved } \neq \\
\text { I\$ }(95 \% \mathrm{Cl})\end{array}$ \\
\hline \multirow[t]{2}{*}{ Reducing salt in bread } & $193,576.23$ & $-946,580.87$ & 672.80 & $0.11 \%$ & $-1,406.93$ \\
\hline & $(-)$ & $(-)$ & $(-)$ & $(-)$ & $(-)$ \\
\hline \multirow{2}{*}{$\begin{array}{l}\text { Treatment targeted to persons with an absolute risk } \\
\text { above } 20 \% \text { in } 10 \text { years (polypill strategy }\end{array}$} & $23,489,613.55$ & $-2,979,727.10$ & $12,108.15$ & $1.98 \%$ & -246.45 \\
\hline & $\begin{array}{c}(22,002,839.35- \\
24,877,996.13)\end{array}$ & $\begin{array}{l}(-3,663,248.39- \\
-2,301,924.52)\end{array}$ & $\begin{array}{l}(11,396.45- \\
12,752.71)\end{array}$ & $\begin{array}{l}(1.86 \%- \\
2.09 \%)\end{array}$ & $\begin{array}{l}(-307.74- \\
-189.68)\end{array}$ \\
\hline \multirow[t]{2}{*}{ Pharmacological therapy for high blood pressure } & $62,251,491.82$ & $41,014,269.81$ & $14,100.16$ & $2.31 \%$ & $2,908.86$ \\
\hline & $\begin{array}{c}(61,201,512.65- \\
63,303,292.70)\end{array}$ & $\begin{array}{c}(40,070,763.64- \\
42,021,481.43)\end{array}$ & $\begin{array}{c}(13,919.53- \\
14,275.31)\end{array}$ & $\begin{array}{c}(2.28 \%- \\
2.33 \%)\end{array}$ & $\begin{array}{c}(2,841.81- \\
2,977.48)\end{array}$ \\
\hline \multirow[t]{2}{*}{ Mass Media Campaign to promote tobacco cessation } & $3,164,785.75$ & $2,053,674.53$ & 644.73 & $0.11 \%$ & $3,186.71$ \\
\hline & $(-)$ & $\begin{array}{l}(2,012,812.78- \\
2,090,361.57)\end{array}$ & $\begin{array}{l}(624.52- \\
666.90)\end{array}$ & $\begin{array}{l}(0.10 \%- \\
0.11 \%)\end{array}$ & $\begin{array}{l}(3,024.42- \\
3,337.92)\end{array}$ \\
\hline \multirow[t]{2}{*}{ Pharmacological therapy of high cholesterol } & $92,751,189.47$ & $81,762,199.07$ & $5,666.16$ & $0.93 \%$ & $14,431.46$ \\
\hline & $\begin{array}{c}(90,559,448.95- \\
94,981,610.94)\end{array}$ & $\begin{array}{l}(79,775,242.39- \\
83,805,632.99)\end{array}$ & $\begin{array}{c}(5,507.87- \\
5,824.03)\end{array}$ & $\begin{array}{l}(0.90 \%- \\
0.95 \%)\end{array}$ & $\begin{array}{c}(14,077.55- \\
14,809.92)\end{array}$ \\
\hline Therapy with Bupropion for & $51,778,301.95$ & $50,318,932.00$ & 846.80 & $0.14 \%$ & $59,433.02$ \\
\hline tobacco cessation & $\begin{array}{c}(50,792,163.89- \\
52,752,733.57)\end{array}$ & $\begin{array}{c}(49,372,843.67- \\
51,286,965.18)\end{array}$ & $\begin{array}{c}(820.26- \\
875.93)\end{array}$ & $\begin{array}{l}(0.13 \%- \\
0.14 \%)\end{array}$ & $\begin{array}{c}(57,819.14- \\
60,906.25)\end{array}$ \\
\hline
\end{tabular}

95\%Cl: 95\% confidence interval, I\$: international dollars - PPP conversion rate (2007) 1.55 Argentinean peso = 1 I\$, DALY: disability adjusted life years, ICER: incremental cost-effectiveness ratio. The ICERs express the results of 1,000 iterations.

* Net Total costs are calculated as Total costs minus the corresponding averted event costs. All costs are measured in 2007 International dollars (I\$).

\# Derived from bootstrapping techniques.

model the impact of some preventive interventions to reducing this burden, as well as estimating their costeffectiveness. Based on our data, the PAR of all the risk factors analyzed explained more than $75 \%$ of the acute CHD events and strokes in men and women. Only high blood pressure explained more than onethird of the events while each one of the other risk factors explained between $14 \%$ and $18 \%$. WHO recently addressed the importance of chronic disease prevention as a neglected health issue in LMIC; achievement of the global goal to reduce chronic disease death rates by $2 \%$ every year would avert 36 million deaths between 2005 and 2015 [75,76]. Achieving this target would also save almost $10 \%$ of the expected

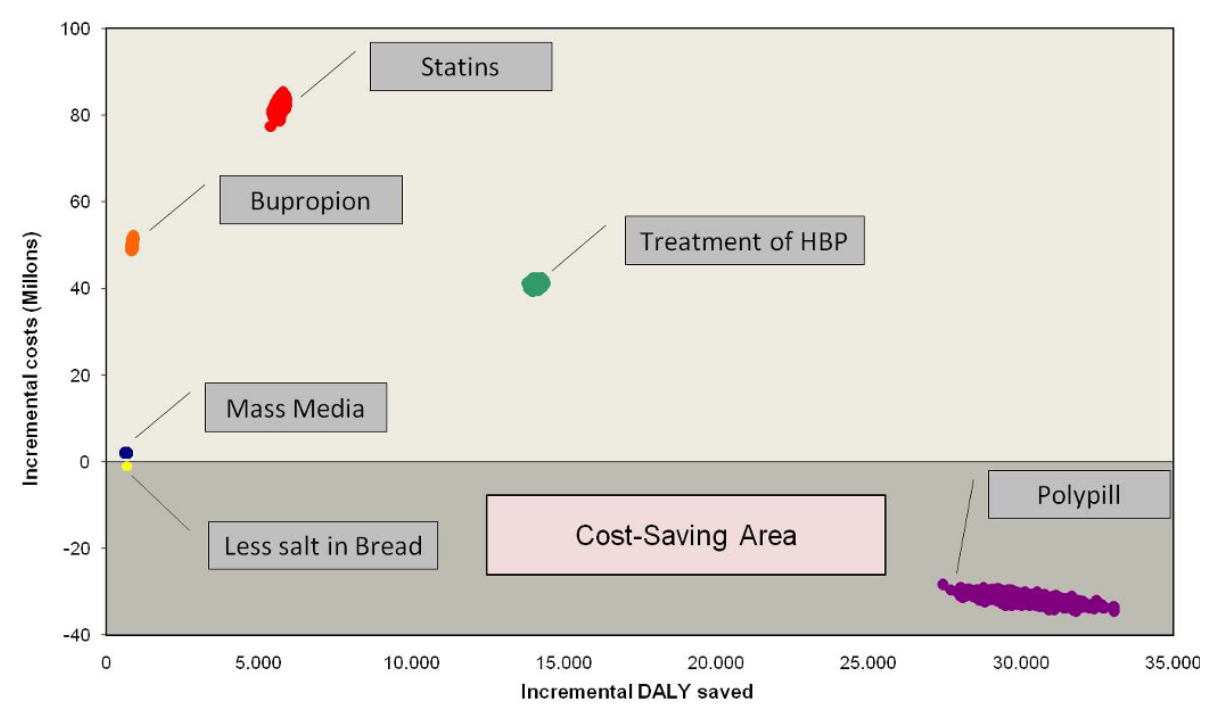

Figure 1 Interventions along the cost-effectiveness plane. Costs are expressed in International dollars (I\$, 2007). 
loss in national income in these settings [7]. Considering the growing burden of cardiovascular disease and costs in developing countries, especially for transitional countries like Argentina, this study is critical to provide local decision-makers with information about cardiovascular disease burden. Furthermore, by comparing the relative costs and health effects of interventions for preventing cardiovascular disease, we can focus policy debate concerning the trade-offs or opportunity costs of financing one intervention over another.

Establishing the cost-effectiveness of preventive interventions for cardiovascular disease in developing country contexts is not straightforward, due to both the paucity of existing evidence, and because there is no universally agreed threshold for considering the costeffectiveness of an intervention to be 'too high' or 'right'. What is acceptable to health and finance decision-makers depends largely on the country context. The Disease Control Priorities Project (DCPP), has identified several chronic disease interventions as cost-effective at a cost of below US $\$ 1,000$ per DALY [77]. However, the affordability of interventions will vary significantly across countries, even among a group of interventions believed to be cost-effective in the global sense. Moreover, sensitivity analysis done as part of the cost effectiveness analysis modeling for the DCPP showed that the cost-effectiveness of public education campaigns at the population level could be very good or far less favorable depending on how much it cost to reach people using a reasonable range of costs. In addition, even a very inexpensive intervention might not be worth implementing if it targets a chronic disease with low prevalence in a given country or region.

In an earlier analysis, Murray et al. [12] modeled selected population-based and individual health interventions to lower high blood pressure and high cholesterol in the epidemiological contexts of developing countries. The authors found that all interventions were highly cost-effective in the sub-region of the Americas to which Argentina belongs.

More recently, Asaria et al., assessed the financial costs and health effects of a voluntary reduction in the salt content of processed foods by manufacturers plus a mass media campaign to encourage dietary change in 23 selected low and middle income countries, including Argentina. They estimated that a $15 \%$ reduction in dietary salt intake in Argentina would save 60,000 lives over the period 2006-2015 at a cost of US\$ 0.14 per capita (equivalent to AR\$ 16.7 million for a population of Argentina (38 millions in 2005) [38].

As compared to these previous studies [12,38], our intervention to decrease salt intake in bread was costsaving, although both our health impact and cost estimates were appreciably lower than those summarized above, partly because we only included a series of oneoff meetings with bread makers from large cities, and also because we used a lower effect size.

In regards to the intervention oriented to reduce high blood pressure and high cholesterol our ICER were remarkably higher than those reported by Murray et al. [12]. The causes of this apparent discrepancy are twofold: firstly, the counterfactual scenario designed by Murray, based on the WHO-CHOICE methodology [71] entails lifting the constraints of the current mix of interventions, using a null scenario of no costs and no interventions as a starting point, as opposed to our assumption that almost half of Argentine population were already receiving treatment; based on the data of the FASRF; and secondly, our cost estimates are considerably higher, which reflects the fact that key intervention resource inputs in Argentina (including human resources, secondary care and drugs) are much more expensive than the regional average. The addition of individual-level interventions with a multi-drug regimen on the basis of opportunistic contact with the health service, as reported by Gaziano et al. [78], has been estimated at US\$ 2.93 per capita in a country like Argentina, but would save a further 50,000 lives over a 10-year period.

Our analyses have shown that the multidrug regimen of four highly effective drugs (polypill strategy, with an annual cost of I\$ 101 or I\$ 32 per capita in 2007) could lead to cost-saving prevention and treatment for subjects with an absolute risk above $20 \%$ in 10 years, with $2 \%$ of reduction in DALY lost to cardiovascular disease even considering a population effectiveness of less than $20 \%$ the potential targeted population. Other treatment cutpoints for this intervention, where ICERs would likely be far higher, were not evaluated, including subjects with lesser CV risk or subjects over age 55 as originally proposed by Wald and Law (53), The study of Gaziano et al about the cost-effectiveness of the Polypill regimen [13] modeled an ICER of less than US\$ 900 for a similar risk population in the Latin American region.

According to the threshold adopted by World Health Organization, an intervention that saves one DALY for less than three times the gross domestic product (GDP) per capita is considered cost-effective, while one that saves a DALY for less than one GDP per capita is deemed very cost-effective [71]. As Argentina's GDP per person in 2007 was I\$13,255 (US\$ 6,644) [79,80], estimated ICER of all interventions analyzed except tobacco cessation with bupropion (I\$ 59,433 per DALY saved) fell well within the 'very cost-effective' or cost-effective category. In fact, two interventions - reducing salt intake in bread and the absolute risk approach therapy with four drugs - were cost-saving. In an earlier study of cost-effectiveness of cardiovascular interventions in 
Buenos Aires, in which we used a counterfactual scenario of no costs and no interventions, most of our interventions were very cost-effective [81]. Should we have used a counterfactual scenario based on what the public health sector was actually spending on the care of cardiovascular disease we would have obtained much lower ICER or even cost-saving interventions like we have found in this study.

In addition, the potential budget impact of the implementation of the four cost saving or cost-effective interventions mentioned above was in the range of I\$ 194 million in 2005. This expenditure would be partly offset by the savings obtained through avoided cardiovascular acute events. Moreover, the financing of these interventions, even considering low population effectiveness according to our conservative scenario, could reduce at least $7 \%$ the cardiovascular disease burden with its consequent health, economic and social impact.

Some limitations of the present work are important to be acknowledged. 1), the risk factors included in the model were limited to those that were specifically addressed in the national survey as they were specifically defined. In this regard, concerning the intake of fruits and vegetables, we were bound to the two defined options as posed in the specific question of the survey: more or less than five servings a week (rather than more or less than five servings a day), which is clearly inappropriate based on WHO recommendations [82]. This limitation prompted us to exclude this risk factor for further analysis. Other risk factors related to diet such as trans fat, low marine omega-3, and low polyunsaturated fat were also excluded due to lack of population based data stressing the importance of obtaining future national-level data on these and other dietary risk factors for future analysis; 2) since the prevalence of risk factors was obtained from self-reports of participants and not from direct measures, they were defined dichotomously or categorically (as having or not having the risk factor) for the calculation of the PAR. This implies that the risk of a particular risk factor behaves like an "all or none" phenomenon, which is obviously not true given the continuous nature of this risk in all of the selected risk factors. In this regard, estimating the theoretical minimum risk exposure distribution would be a more appropriate method should this had been possible; 3) we have just modeled interventions that either had been tested in pilot studies (i.e.: reducing salt in bread) or were considered key data to model the intervention (i.e.: just $11 \%$ of total smokers in Argentina as potential quitters to model the impact of tobacco cessation with bupropion); 4), we did nor model potential side effects of the multidrug intervention. Ignoring side effects in the analysis could overestimate the ICER of the polypill strategy. 5) our study does not assume any benefit from the pharmacological interventions in the population that is already receiving treatment, as if they were appropriately controlled, which is not true. No matter that this is aligned with our conservative estimates, the ICER of high blood pressure or high cholesterol therapy look less attractive in terms of reduction of disease burden or cost-effectiveness; 6) as in all modeling studies, our study synthesized data from many sources and used several assumptions in the design of the model. As real life decision making tools, these types of model-based studies are explicit analyses to help health priority setting, and are not a "search of the ultimate truth"; and 7) some inputs, as it is also commonplace in modeling studies, were derived from international sources. This was done mainly with relative measures such as relative risks of different cardiovascular risk factors, or relative effects of interventions, which on the other hand, are widely thought to be more generalizable from setting to setting.

\section{Conclusions}

Overall, evidence exists to conclude that there are important clinical as well as economic consequences of cardiovascular disease, consequences that are not only important to the individual and his/her family but also to the economy at large. At the same time, there are severe gaps in the evidence that call for more research into the avoidable burden of cardiovascular disease, in particular for developing countries. Despite the increasing burden of cardiovascular disease in Argentina, ranking first over the last decades as a cause of mortality and morbidity, national health programs and policies are still focused on interventions aimed to tackle communicable diseases or perinatal or childhood conditions, overlooking actions and programs targeted to lifestyle and nutritional changes in the population at large or pharmacological interventions to reduce cardiovascular disease burden in high risk people.

In conclusion, most of the interventions selected were cost-saving or very cost-effective according to WHO standards. Moreover, the financing of these interventions could reduce at least $5 \%$ the cardiovascular disease burden with its consequent health, economic and social impact. This study aims to inform policy makers on resource-allocation decisions to reduce the burden of CVD, especially for middle-income developing countries like Argentina.

\section{Abbreviations}

95\%Cl: 95\% confidence interval; AMl: acute myocardial infarction; CEAC: costeffectiveness acceptability curves; CHD: coronary heart disease; DALY: disability-adjusted life years; DCPP: Disease Control Priorities Project; GDP: Gross Domestic Product; I\$: international dollars; ICER: Incremental CostEffectiveness Ratio; LMIC: Iow and middle-income countries; PAF: Population Attributable Fraction; PYLL: Potential Years of Life Lost 


\section{Acknowledgements}

We would like to thank Daniel Comandé, our librarian, for his invaluable contribution to this work.

Lisandro Colantonio is Fogarty International Clinical Research Fellow 20092010 through the International Clinical Research Fellows Program at Vanderbilt Institute for Global Health, Vanderbilt University in Nashville, TN (R24 TW007988).

\section{Author details}

${ }^{1}$ Institute for Clinical Effectiveness and Health Policy (IECS), Buenos Aires, Argentina. ${ }^{2}$ Division of Family and Community Medicine, Hospital Italiano de Buenos Aires, Buenos Aires, Argentina. ${ }^{3}$ Programa de Prevención del Infarto en Argentina (PROPIA), Universidad Nacional de La Plata, Buenos Aires, Argentina. ${ }^{4}$ Centro de Endocrinología Experimental y Aplicada (CENEXA), Universidad Nacional de La Plata, Buenos Aires, Argentina.

\section{Authors' contributions}

AR conceived the study, coordinated the teamwork and participated in its design and analysis. He also led the writing of the manuscript. LC carried out the modeling in Excel and Python, and participated in literature search and drafting of the manuscript. AB participated in the literature search, carried out the assessment of measures of effect for conditions and risk factors, and for effectiveness of interventions. AA and KK also participated in the literature search and abstraction of measures of effects. APR and SGM participated in the design of the study and made substantial statistical contributions. LG participated in the modeling design in Python. JC took responsibility for assessing economic disease impacts and costing of the interventions, and helped in the cost effectiveness analysis. FA made substantial contributions in the CEA. All authors read and approved the final manuscript.

\section{Competing interests}

This study was funded by an independent grant from the Comision "Salud Investiga" of the Argentine Ministry of Health (Becas Carrillo-Oñativia).

The authors declare that they have no competing interests.

Received: 14 January 2010 Accepted: 20 October 2010 Published: 20 October 2010

\section{References}

1. Yusuf S, Hawken S, Ounpuu S, Dans T, Avezum A, Lanas F, McQueen M, Budaj A, Pais P, Varigos J, Lisheng L: Effect of potentially modifiable risk factors associated with myocardial infarction in 52 countries (the INTERHEART study): case-control study. Lancet 2004, 364:937-952.

2. Argentina: indicadores básicos 2008. Buenos Aires, Argentina: Ministerio de Salud 2009.

3. Ministerio de Salud de la Nación, Dirección de Prevención y Protección de la Salud: Boletín de Vigilancia. Enfermedades No Transmisibles y Factores de Riesgo. Buenos Aires: Ministerio de Salud de la Nación, Dirección de Prevención y Protección de la Salud 2009.

4. Lopez AD, Mathers CD, Ezzati M, Jamison DT, Murray CJ: Global and regional burden of disease and risk factors, 2001: systematic analysis of population health data. Lancet 2006, 367:1747-1757.

5. Primera Encuesta Nacional de Factores de Riesgo: Buenos Aires: Ministerio de Salud y Ambiente de la Nación, First 2006.

6. Schargrodsky $\mathrm{H}$, Hernandez-Hernandez R, Champagne BM, Silva H, Vinueza R, Silva Aycaguer LC, Touboul PJ, Boissonnet CP, Escobedo J, Pellegrini F, et al: CARMELA: assessment of cardiovascular risk in seven Latin American cities. Am J Med 2008, 121:58-65.

7. Abegunde DO, Mathers CD, Adam T, Ortegon M, Strong K: The burden and costs of chronic diseases in low-income and middle-income countries. Lancet 2007, 370:1929-1938.

8. Lanas F, Avezum A, Bautista LE, Diaz R, Luna M, Islam S, Yusuf S: Risk factors for acute myocardial infarction in Latin America: the INTERHEART Latin American study. Circulation 2007, 115:1067-1074.

9. Murray CJL, Lopez AD: The global burden of disease: a comprehensive assessment of mortality and disability from diseases, injuries, and risk factors in 1990 and projected to 2020. Cambridge, MA: Harvard University Press 1996.

10. The World Health report: Reducing Risks, Promoting Healthy Life. Geneva: World Health Organization 2002.
11. Rubinstein A, Belizan M, Discacciati V: Are economic evaluations and health technology assessments increasingly demanded in times of rationing health services? The case of the Argentine financial crisis. International journal of technology assessment in health care 2007, 23:169-176.

12. Murray CJ, Lauer JA, Hutubessy RC, Niessen L, Tomijima N, Rodgers A, Lawes CM, Evans DB: Effectiveness and costs of interventions to lower systolic blood pressure and cholesterol: a global and regional analysis on reduction of cardiovascular-disease risk. Lancet 2003, 361:717-725.

13. Gaziano TA, Opie LH, Weinstein MC: Cardiovascular disease prevention with a multidrug regimen in the developing world: a cost-effectiveness analysis. Lancet 2006, 368:679-686.

14. Nissinen A, Berrios X, Puska P: Community-based noncommunicable disease interventions: lessons from developed countries for developing ones. Bull World Health Organ 2001, 79:963-970.

15. Estadísticas vitales. Información básica - 2005: Buenos Aires: Dirección de Estadísticas e Información de Salud. Secretaría de Políticas, Regulación y Relaciones Sanitarias. Ministerio de Salud y Ambiente de la Nación 2006.

16. Wilson PW, D'Agostino RB, Levy D, Belanger AM, Silbershatz H, Kannel WB: Prediction of coronary heart disease using risk factor categories. Circulation 1998, 97:1837-1847.

17. Egresos de establecimientos oficiales según variables seleccionadas. República Argentina - Año 2000: Buenos Aires: Secretaría de Políticas, Regulación y Relaciones Sanitarias. Ministerio de Salud 2003.

18. Murray CJ: Quantifying the burden of disease: the technical basis for disability-adjusted life years. Bull World Health Organ 1994, 72:429-445.

19. Barendregt JJ, Van Oortmarssen GJ, Vos T, Murray CJ: A generic model for the assessment of disease epidemiology: the computational basis of DisMod II. Popul Health Metr 2003, 1:4.

20. Victorian Burden of Disease Study. Mortality and morbidity in 2001. Book Victorian Burden of Disease Study. Mortality and morbidity in 2001 City: Public Health Group, Rural and Regional Health and Aged Care Services Division. Victorian Government Department of Human Services 2005.

21. Mathers C, Vos T, Stevenson C: The burden of disease and injury in Australia. Book The burden of disease and injury in Australia City: Australian Institute of Health and Welfare 1999.

22. Bassi S: A primer on python for life science researchers. PLoS Comput Biol 2007, 3:e199.

23. Sellers DE, Crawford SL, Bullock K, McKinlay JB: Understanding the variability in the effectiveness of community heart health programs: a meta-analysis. Soc Sci Med 1997, 44:1325-1339.

24. Cavill N, Bauman A: Changing the way people think about healthenhancing physical activity: do mass media campaigns have a role? J Sports Sci 2004, 22:771-790.

25. Finlay SJ, Faulkner G: Physical activity promotion through the mass media: inception, production, transmission and consumption. Prev Med 2005, 40:121-130.

26. Marshall AL, Owen N, Bauman AE: Mediated approaches for influencing physical activity: update of the evidence on mass media, print, telephone and website delivery of interventions. J Sci Med Sport 2004, 7:74-80.

27. Kahn EB, Ramsey LT, Brownson RC, Heath GW, Howze EH, Powell KE, Stone EJ, Rajab MW, Corso P: The effectiveness of interventions to increase physical activity. A systematic review. Am J Prev Med 2002, 22:73-107.

28. He FJ, MacGregor GA: Effect of longer-term modest salt reduction on blood pressure. Cochrane Database Syst Rev 2004, CD004937.

29. Hooper L, Bartlett C, Davey SG, Ebrahim S: Advice to reduce dietary salt for prevention of cardiovascular disease. Cochrane Database Syst Rev 2004, CD003656.

30. Jeffery RW: Community programs for obesity prevention: the Minnesota Heart Health Program. Obes Res 1995, 3(Suppl 2):283s-288s.

31. Miles A, Rapoport L, Wardle J, Afuape T, Duman M: Using the mass-media to target obesity: an analysis of the characteristics and reported behaviour change of participants in the BBC's 'Fighting Fat, Fighting Fit' campaign. Health Educ Res 2001, 16:357-372.

32. Gepkens A, Gunning SL: Interventions to reduce socioeconomic health differences: A review of the international literature. Eur J Pub Health 1996, 6:218-226

33. Foerster SB, Kizer KW, Disogra LK, Bal DG, Krieg BF, Bunch KL: California's "5 a day-for better health!" campaign: an innovative population-based 
effort to effect large-scale dietary change. Am J Prev Med 1995, 11:124-131.

34. Samuels SE: Project LEAN: a national campaign to reduce dietary fat consumption. Am J Health Promot 1990, 4:435-440.

35. Heimendinger J, Chapelsky D: The National 5 A Day for Better Health Program. Adv Exp Med Biol 1996, 401:199-206.

36. Puska P, Tuomilehto J, Nissinen A, Salonen JT, Vartiainen E, Pietinen P, Koskela K, Korhonen HJ: The North Karelia project: 15 years of community-based prevention of coronary heart disease. Ann Med 1989, 21:169-173.

37. Farquhar JW, Fortmann SP, Flora JA, Taylor CB, Haskell WL, Williams PT, Maccoby N, Wood PD: Effects of communitywide education on cardiovascular disease risk factors. The Stanford Five-City Project. JAMA 1990, 264:359-365

38. Asaria P, Chisholm D, Mathers C, Ezzati M, Beaglehole R: Chronic disease prevention: health effects and financial costs of strategies to reduce salt intake and control tobacco use. Lancet 2007, 370:2044-2053.

39. Gagne L: The 2005 British Columbia Smoking Cessation Mass Media Campaign and short-term changes in smoking. J Public Health Manag Pract 2007, 13:296-306

40. Levy AS, Stokes RC: Effects of a health promotion advertising campaign on sales of ready-to-eat cereals. Public Health Rep 1987, 102:398-403.

41. Macaskill P, Pierce JP, Simpson JM, Lyle DM: Mass media-led antismoking campaign can remove the education gap in quitting behavior. Am J Public Health 1992, 82:96-98.

42. Secker-Walker RH, Gnich W, Platt S, Lancaster T: Community interventions for reducing smoking among adults. Cochrane Database Syst Rev 2002, CD001745.

43. Apro N, Gil GP, Rodríguez J, Puntieri MV, Ferreyra VA, Gulivart VL, Freile GE, Gambarotta L, Blasco R, Aguilar V, et al: Relevamiento del uso de sal en los productos de panaderías artesanales de la República Argentina e implementación de acciones de desarrollo, tecnológicas, de asistencia técnica y extensión con el objeto de bajar su utilización y consumo. Promoción de la Salud cardiovascular y la alimentación saludable Estudios y experiencias Buenos Aires: Ministerio de Salud 2005.

44. He FJ, MacGregor GA: How far should salt intake be reduced? Hypertension 2003, 42:1093-1099.

45. Ferrante D, Levy D, Peruga A, Compton C, Romano E: The role of public policies in reducing smoking prevalence and deaths: the Argentina Tobacco Policy Simulation Model. Rev Panam Salud Publica 2007, 21:37-49.

46. Gimpel NE, Schoj V, Rubinstein A: Quality management of hypertension in primary care: do physicians treat patients' blood pressure level or cardiovascular risk? Quality in Primary Care 2006, 14:211-217.

47. Hemmelgarn BR, McAlister FA, Grover S, Myers MG, McKay DW, Bolli P, Abbott C, Schiffrin EL, Honos G, Burgess E, et al: The 2006 Canadian Hypertension Education Program recommendations for the management of hypertension: Part I-Blood pressure measurement, diagnosis and assessment of risk. Can J Cardiol 2006, 22:573-581.

48. Third Report of the National Cholesterol Education Program (NCEP) Expert Panel on Detection, Evaluation, and Treatment of High Blood Cholesterol in Adults (Adult Treatment Panel III) final report. Circulation 2002, 106:3143-3421.

49. Hughes J, Stead L, Lancaster T: Antidepressants for smoking cessation. Cochrane Database Syst Rev 2004, CD000031.

50. Hurt RD, Sachs DP, Glover ED, Offord KP, Johnston JA, Dale LC, Khayrallah MA, Schroeder DR, Glover PN, Sullivan CR, et al: A comparison of sustained-release bupropion and placebo for smoking cessation. $N$ Engl J Med 1997, 337:1195-1202.

51. Swan GE, McAfee T, Curry SJ, Jack LM, Javitz H, Dacey S, Bergman K. Effectiveness of bupropion sustained release for smoking cessation in a health care setting: a randomized trial. Arch Intern Med 2003, 163:2337-2344.

52. Guía Nacional de Tratamiento de la adicción al tabaco. Book Guía Nacional de Tratamiento de la adicción al tabaco City: Ministerio de Salud y Ambiente de la Nación 2005

53. Wald NJ, Law MR: A strategy to reduce cardiovascular disease by more than $80 \%$. BMJ 2003, 326:1419.

54. Yusuf S: Two decades of progress in preventing vascular disease. Lancet 2002, 360:2-3.

55. Baigent C, Keech A, Kearney PM, Blackwell L, Buck G, Pollicino C, Kirby A Sourjina T, Peto R, Collins R, Simes R: Efficacy and safety of cholesterol- lowering treatment: prospective meta-analysis of data from 90,056 participants in 14 randomised trials of statins. Lancet 2005, 366:1267-1278.

56. Blanco P, Gagliardi J, Higa C, Dini A, Guetta J, di Toro D, Botto F, Sarmiento RA: Infarto agudo de miocardio. Resultados de la Encuesta SAC 2005 en la República Argentina. Rev Argent Cardiol 2007, 75:163-170.

57. Elizari MV, Martinez JM, Belziti C, Ciruzzi M, Perez dela Hoz R, Sinisi A, Carbajales J, Scapin O, Garguichevich J, Girotti L, Cagide A: Morbidity and mortality following early administration of amiodarone in acute myocardial infarction. GEMICA study investigators, GEMA Group, Buenos Aires, Argentina. Grupo de Estudios Multicentricos en Argentina. European heart journal 2000, 21:198-205.

58. Gurfinkel EP, Bozovich GE, Dabbous O, Mautner B, Anderson F: Socio economic crisis and mortality. Epidemiological testimony of the financial collapse of Argentina. Thrombosis journal [electronic resource] 2005, 3:22.

59. Rojas Jl, Zurru MC, Patrucco L, Romano M, Riccio PM, Cristiano E: Registro de enfermedad cerebrovascular isquémica. 2006, 66:547-551.

60. Sposato LA, Esnaola MM, Zamora R, Zurru MC, Fustinoni O, Saposnik G: Quality of ischemic stroke care in emerging countries: the Argentinian National Stroke Registry (ReNACer). Stroke 2008, 39:3036-3041.

61. Sposato LA, EM M, Cirio JJ, Zurru MC, Rey RC, Domínguez R, Lepera S, Rotta Escalante R, Herrera G, Abiusi $G$, et al: Acute ischemic stroke treatment in Argentina. ReNACer. Argentinian Stroke Registry. 2006.

62. Pichón-Rivière A, Regueiro A, Souto A, Augustovski F: Base de datos de costos sanitarios Argentinos. Book Base de datos de costos sanitarios Argentinos City: Instituto de Efectividad Clínica y Sanitaria (IECS) 2004.

63. Ministerio de Salud: Resolución 372/2001. Aranceles de los Hospitales Públicos de Gestión Descentralizada. Book Resolución 372/2001. Aranceles de los Hospitales Públicos de Gestión Descentralizada City: Superintendencia de Servicios de Salud 2001, 12, vol. Resolución 372/2001. pp. 12

64. Ministerio de Salud: Resolución 488/2002. Normas y módulos para los Hospitales Públicos de Gestión Descentralizada. Unidad Hospital Público (UHP). Book Resolución 488/2002. Normas y módulos para los Hospitales Públicos de Gestión Descentralizada. Unidad Hospital Público (UHP) City: Superintendencia de Servicios de Salud 2002, vol. Resolución 488/2002.

65. Manual Farmacéutico On Line. [http://www.alfabeta.net/mf.xtp].

66. Comisión Nacional de Medicamentos Remediar (personal communication): Buenos Aires: Ministerio de Salud 2007.

67. Compras de medicamentos, años 2004-2006 (personal communication): Neuquén: Subsecretaría de Salud 2007.

68. World Economic Outlook Database, April 2009. [http://www.imf.org/ external/pubs/ft/weo/2009/01/weodata/index.aspx].

69. Fox-Rushby JA, Hanson K: Calculating and presenting disability adjusted life years (DALYs) in cost-effectiveness analysis. Health policy and planning 2001, 16:326-331.

70. Sachs JD: Macroeconomics and Health: Investing in Health for Economic Development. Report of the Commission on Macroeconomics and Health. Geneva: World Health Organization 2001.

71. Baltussen RMPM, Adam T, Tan-Torres Edejer T, Hutubessy RCW, Acharya A, Evans DB, Murray CJ: Making choices in health : WHO guide to costeffectiveness analysis. Geneva: World Health Organization 2003.

72. World Bank, International Comparison Program database. [http://data. worldbank.org/].

73. Weinstein MC: Recent developments in decision-analytic modelling for economic evaluation. PharmacoEconomics 2006, 24:1043-1053.

74. Halpern EF, Weinstein MC, Hunink MG, Gazelle GS: Representing both firstand second-order uncertainties by Monte Carlo simulation for groups of patients. Med Decis Making 2000, 20:314-322.

75. World Health Organization, Department of Chronic Diseases and Health Promotion: Preventing chronic diseases : a vital investment : WHO global report. Geneva: World Health Organization 2005.

76. Strong K, Mathers C, Leeder S, Beaglehole R: Preventing chronic diseases: how many lives can we save? Lancet 2005, 366:1578-1582.

77. Jamison DT: Chapter 1. Investing in Health. In Disease Control Priorities in Developing Countries. Edited by: Jamison DT, Breman JG, Measham AR, Alleyne G, Claeson M, Evans DB, Jha P, Mills A, Musgrove P. Washington, DC: Oxford University Press and The World Bank; , Second 2006:.

78. Lim SS, Gaziano TA, Gakidou E, Reddy KS, Farzadfar F, Lozano R, Rodgers A: Prevention of cardiovascular disease in high-risk individuals in lowincome and middle-income countries: health effects and costs. Lancet 2007, 370:2054-2062. 
79. Population 2006. [http://siteresources.worldbank.org/DATASTATISTICS/ Resources/POP.pdf].

80. Total Gross Domestic Product (GDP) 2006. [http://siteresources.worldbank. org/DATASTATISTICS/Resources/GDP.pdf].

81. Rubinstein A, Garcia Marti S, Souto A, Ferrante D, Augustovski F: Generalized cost-effectiveness analysis of a package of interventions to reduce cardiovascular disease in Buenos Aires, Argentina. Cost Eff Resour Alloc 2009, 7:10.

82. World Health Organization: Prevención de las enfermedades cardiovasculares : guía de bolsillo para la estimación y el manejo del riesgo cardiovascular. Ginebra: Organización Mundial de la Salud 2008.

83. Lewington S, Clarke R, Qizilbash N, Peto R, Collins R: Age-specific relevance of usual blood pressure to vascular mortality: a meta-analysis of individual data for one million adults in 61 prospective studies. Lancet 2002, 360:1903-1913.

84. Miura K, Daviglus ML, Dyer AR, Liu K, Garside DB, Stamler J, Greenland P: Relationship of blood pressure to 25 -year mortality due to coronary heart disease, cardiovascular diseases, and all causes in young adult men: the Chicago Heart Association Detection Project in Industry. Arch Intern Med 2001, 161:1501-1508.

85. Lloyd-Jones DM, Evans JC, Levy D: Hypertension in adults across the age spectrum: current outcomes and control in the community. JAMA 2005, 294:466-472.

86. Huxley R, Barzi F, Woodward M: Excess risk of fatal coronary heart disease associated with diabetes in men and women: meta-analysis of 37 prospective cohort studies. BMJ 2006, 332:73-78.

87. Bogers RP, Bemelmans WJ, Hoogenveen RT, Boshuizen HC, Woodward M, Knekt P, van Dam RM, Hu FB, Visscher TL, Menotti A, et al: Association of overweight with increased risk of coronary heart disease partly independent of blood pressure and cholesterol levels: a meta-analysis of 21 cohort studies including more than 300000 persons. Archives of internal medicine 2007, 167:1720-1728.

88. Ezzati M, López AD: Smoking and oral tobacco use. In Comparative Quantification of Health Risks: Global and Regional Burden of Disease Attributable to Selected Major Risk Factors. Edited by: Ezzati M, López AD, Rodgers A, Murray CJL. Geneva, Switzerland: World Health Organization; 2004:883-957.

89. CDC SAMMEC. CPS-II. Unpublished estimates provided by American Cancer Society (ACS). See Thun MJ, Day-Lally C, Myers DG, et al. Trends in tobacco smoking and mortality from cigarette use in Cancer Prevention Studies I (1959 through 1965) and II (1982 through 1988). In: Changes in cigarette-related disease risks and their implication for prevention and control. Smoking and Tobacco Control Monograph 8. Bethesda, MD: US Department of Health and Human Services, Public Health Service, National Institutes of Health, National Cancer Institute 1997; 305-382. NIH Publication no. 97-1213. In Book CDC SAMMEC. CPS-II. Unpublished estimates provided by American Cancer Society (ACS). Edited by: See Thun MJ, Day-Lally C, Myers DG. Bethesda, MD: US Department of Health and Human Services, Public Health Service, National Institutes of Health, National Cancer Institute; 1997:305-382, Trends in tobacco smoking and mortality from cigarette use in Cancer Prevention Studies I (1959 through 1965) and II (1982 through 1988). In: Changes in cigarette-related disease risks and their implication for prevention and control. Smoking and Tobacco Control Monograph 8

90. Hu G, Tuomilehto J, Silventoinen K, Sarti C, Mannisto S, Jousilahti P: Body mass index, waist circumference, and waist-hip ratio on the risk of total and type-specific stroke. Archives of internal medicine 2007, 167:1420-1427.

91. Amarenco P, Labreuche J, Lavallee P, Touboul PJ: Statins in stroke prevention and carotid atherosclerosis: systematic review and up-todate meta-analysis. Stroke 2004, 35:2902-2909.

92. Lee CD, Folsom AR, Blair SN: Physical activity and stroke risk: a metaanalysis. Stroke 2003, 34:2475-2481.

\section{Pre-publication history}

The pre-publication history for this paper can be accessed here: http://www.biomedcentral.com/1471-2458/10/627/prepub

doi:10.1186/1471-2458-10-627

Cite this article as: Rubinstein et al:: Estimation of the burden of cardiovascular disease attributable to modifiable risk factors and costeffectiveness analysis of preventative interventions to reduce this burden in Argentina. BMC Public Health 2010 10:627.

\section{Submit your next manuscript to BioMed Central and take full advantage of:}

- Convenient online submission

- Thorough peer review

- No space constraints or color figure charges

- Immediate publication on acceptance

- Inclusion in PubMed, CAS, Scopus and Google Scholar

- Research which is freely available for redistribution

Submit your manuscript at www.biomedcentral.com/submit
Biomed Central 